\title{
Etiology and biodistribution of enterobacteria and parasites, and their associated environmental risk factors among children under 5 years old with diarrhea in East-Central Gabon
}

\section{Rolande MABIKA MABIKA}

University of Sciences and Technology of Masuku

\section{Sandrine Lydie OYEGUE-LIABAGUI}

Université des Sciences et Techniques de Masuku: Universite des Sciences et Techniques de Masuku

Franck Mounioko

Université des Sciences et Techniques de Masuku: Universite des Sciences et Techniques de Masuku

\section{Serge Ely DIBAKOU}

CIRMF: Centre International de Recherches Medicales de Franceville

\section{Arnaud MONGO DELIS}

Centre Traitement Ambulatoire de Koula-Moutou

\section{Marie Gabrielle MOUSSAVOU}

Centre Hospitalier Régional Paul Moukambi

\section{Jean-Bernard LEKANA-DOUKI}

CIRMF: Centre International de Recherches Medicales de Franceville

\section{Alain SOUZA}

Université des Sciences et Techniques de Masuku: Universite des Sciences et Techniques de Masuku Jean Fabrice YALA ( $\nabla$ yalajeanfabrice@gmail.com )

Université des Sciences et Techniques de Masuku (USTM)

\section{Research Article}

Keywords: Diarrhea, Children under 5 years old, Bacteria, Parasite, Risk factor, Koula-Moutou, Gabon

Posted Date: December 21st, 2020

DOI: https://doi.org/10.21203/rs.3.rs-131619/v1

License: (c) (i) This work is licensed under a Creative Commons Attribution 4.0 International License. Read Full License 


\section{Abstract \\ Background}

Better knowledge of endogenous germs and their associated demographic and environmental risk factors in a locality are essential to treat childhood diarrheal diseases. The aim of the study was to identify and characterize bacterial and parasitic pathogens responsible for childhood diarrhea, and to identify environmental risk factors associated with diarrhea in children under 5 years old living in Koula-Moutou, East-Central Gabon.

\section{Methods}

A cross-sectional study was performed from May 2016 to February 2018. One-hundred and thirty-two (132) children under 5 years old were enrolled. The detection of pathogens in stool samples was performed using microscopic examination and MIF concentration for parasites, and conventional culture on selective media for enterobacteria.

\section{Results}

The prevalence of diarrheal pathogens was $46.1 \%$, including bacterial enteropathogens $(25.5 \%)$ and parasites $(20.6 \%)$. A total of 228 pathogenic organisms were isolated, including 199 bacterial strains $(87.3 \%)$ and 29 parasites (12.7\%). The specific richness of the isolated enterobacteria was 24 species with a high prevalence of E. coli (39.8\%), including $26.7 \%$ for the diarrheal cases and $13.1 \%$ for the controls. Twelve (12) parasite species were also isolated and the most common types of parasites were rhizopods (44.8\%), which accounted for $37.9 \%$ of the diarrheal cases and $6.9 \%$ of the controls. Univariate analysis showed that the presence of watercourses $(O R=3.37)$ and domestic animals $(O R=1.65)$ were significant risk factors for diarrhea.

\section{Conclusion}

The findings show a high prevalence of bacterial enteropathogens but a low rate of parasites and bacteria-parasite co-infection in the study area. Risk factors associated with diarrhea among children under 5 years old were the presence of watercourses and domestic animals. These findings highlight the need to strengthen the routine examination of diarrheic stool samples for the diagnosis of pathogenic organisms. Further analyses are required to better understand the etiologies and risk factors associated with the transmission of bacteria and parasites in rural, semi-urban and urban regions of Gabon.

\section{Background}


Diarrheal diseases remain the second cause of preventable childhood morbidity and mortality. They are responsible for $9 \%$ of global deaths among children under 5 years old $(1,2)$, despite technological advances and awareness programs issued by the World Health Organization (WHO) and the increased use of oral rehydration therapy in recent decades $(3,4)$. Today, acute diarrhea still represents a major public health issue worldwide and about $80 \%$ of diarrheal deaths in children under two years old occur in South-East Asia and sub-Saharan Africa $(5,6)$.

Infectious and contagious diarrhea is common in developing countries where the risk of transmission is even greater because of the appalling environmental conditions. They are the result of non-sanitary elimination of human wastes, very limited access to safe water, poor hygiene practices, and the means of food conservation and cooking $(7,8)$. In addition, the density of urbanization and the increase of populations in cities can also be risk factors contributing to the development and the contraction of diseases in young children (9).

Diarrheal diseases are mostly caused by enteric pathogens, including bacteria, viruses, and protozoa (10). Germs such as rotaviruses, Escherichia coli and other pathogenic bacteria, are the most common etiological agents in young children which induce moderate to severe diarrhea $(11,12)$. In addition, the economic and health impacts due to diarrheal diseases would require monitoring in order to better understand the risk factors leading to their occurrence. Thus, reducing the morbidity of diarrheal diseases requires a comprehensive approach of this pathology that combines the study of therapeutic management, socio-economic, demographic and environmental conditions, the ecology of the pathogens responsible, and knowledge of local communities $(5,13)$.

In Gabon, like everywhere else in sub-Saharan Africa, the epidemiological plan is largely dominated by communicable diseases which are classified as the first group responsible for morbidity. Ninety percent $(90 \%)$ of the causes of death for children under five years old in this country are due to malaria $(29 \%)$, prematurity $(15 \%)$, acute respiratory infections $(11 \%)$, HIV $(10 \%)$, and diarrheal diseases $(6 \%)(14,15)$. The prevalence of diarrheal diseases was 50\% in 2008 and $15.8 \%$ in 2012 in the city of Libreville, and the most vulnerable population was children under 15 years old $(15,16)$. However, the national prevalence of endemic diarrhea remains only poorly documented and prospections on the etiology of infectious diarrheas are rarely done routinely. Furthermore, it is also necessary to consider the specific etiological characteristics of the different cities because bacterial etiology often leads to systematic and abusive antibiotic therapy (17). Therefore, better knowledge of the possible infectious causes and their associated risk factors will improve diarrhea treatment methods in order to preserve effective antibiotics and fight off antibiotic resistance.

The aims of this study were to 1) estimate the prevalence of parasitic and bacterial pathogens, and their associated risk factors in children under 5 years old with diarrhea living in Koula-Moutou and 2) make a map of parasitic and bacterial pathogens responsible for childhood diarrhea in Koula-Moutou, Gabon.

\section{Methods}




\section{Study area}

This study was conducted at the Paul Moukambi Regional Hospital Center (PMRHC) and different districts in Koula-Moutou, Gabon. Koula-Moutou is the administrative capital of the Ogooué-Lolo Province and a semi-urban area in East-Central Gabon ( $1^{\circ} 13^{\prime} 10^{\prime \prime} S$ and $12^{\circ} 28^{\prime} 0^{\prime \prime} \mathrm{E}$ ) (Figure 1). The city of KoulaMoutou had an estimated population of 23,629 inhabitants in 2017 (18). Among the twenty-eight (28) neighborhoods listed in this study, only twenty-seven (27) are currently listed by the municipal authorities of the province (Figure 1).

\section{Study design and population}

A cross-sectional study was carried out in Koula-Moutou from May 2016 to February 2018. The different sampling campaigns were carried out intermittently and during the rainy season which corresponds to the peak of diarrheal disease (19). Samples were collected in the pediatric and emergency wards of the PMRHC and different districts of the city. The definition of "diarrhea case" was based on the recommendations of the World Health Organization (8).

The study population was composed of 132 children aged 0 to 70 months old living in the selected study sites and presenting acute diarrhea or no diarrhea. Children with acute diarrhea, hospitalized patients, children treated on an outpatient or consultant basis and who had not been on antibiotic therapy for more than 24 hours prior to the sampling were included. Children older than 71 months and under treatment for more than 24 hours prior to sampling were excluded from this study. Controls selected during the same period were children who had no history of diarrheal episode over a period of 15 days prior to their recruitment in this study.

Written informed consent was obtained from the parents or guardians of the participating children. For each participant, demographic characteristics (age, sex, origin), clinical characteristics (fever, vomiting, duration of diarrhea before consultation, the type or absence of treatment), and environmental and living conditions (type of drinking water, presence of toilets or a latrine, presence of watercourses, presence of domestic animals, sanitary condition of the plots, proximity of livestock farms) were collected on a standard survey form. Children aged 24 months old or less were considered to be exposed to the disease.

\section{Sample collection}

Stool samples were collected in sterile containers from diarrheal pediatric patients. In infants, fecal samples were collected by rectal swab. Each vial was identified by the code number of the participant.

\section{Sample examination}

Macroscopic examination was performed according to the Bristol scale on each stool sample to note the appearance, consistency, color and possible presence of blood and mucus. A microscopic examination after specific staining with lugol and merthiolate formalin iodine for the detection of parasites and Gram 
staining for the appreciation of the morphology and composition of the bacterial flora was carried out on each stool sample.

\section{Detection of parasites}

A small amount of the stool sample equivalent to the size of a pea was mixed with a drop of saline $(0.9 \%$ sodium chloride) and covered with a coverslip. A drop of lugol and merthiolate formalin iodine were also added on a small stool sample and the slide was examined under a light microscope to observe motile parasites. This method is used to detect intestinal protozoa and soil-transmitted helminths (STHs). The sample was considered negative if no intestinal protozoa or helminths were found on the entire slide. The merthiolate-iodine-formaldehyde (thimerosal) concentration (MIFc) method was also used. The MIFc method was carried out as described by M'bondoukwé et al. (20). Samples were considered positive upon the detection of a single parasite.

\section{Isolation and identification of bacterial strains}

Fecal samples were streaked on selective agar media for the isolation of Gram negative bacilli: Hektoen, Salmonella-Shigella, for the isolation of strains of Salmonella, Shigella; Methylene Blue Eosin (MBE) for the isolation of $E$. coli and Drigalski for other enterobacteria. Briefly, the stool samples were streaked on the agar surface. The media were incubated at $37^{\circ} \mathrm{C}$ for 24 hours. After the isolation of pure colonies, the identification of the strains was carried out using the standard biochemical system Api 20E (Biomérieux, Marcy l'Etoile, France) and the results were interpreted using the Api web ${ }^{T M}$ stand alone V 1.2.1 software (Biomérieux, Marcy l'Etoile, France). However, no confirmation by serotyping was done for Salmonella, Shigella and Yersinia isolates.

\section{Ethical considerations}

The study was approved by the Gabonese National Ethics Committee for Research and the Ministry of Health (PROT N 0020/2015/SG/CNE). The study protocol was approved and authorized by the CenterEast General Direction of Health, the Direction of the Ogooué-Lolo Provincial Academy and the Provincial Direction of Family and Social Welfare. Stool samples were collected from children after obtaining their parents' or guardians' written informed consent.

\section{Statistical analysis}

The data collected were typed in an Excel spreadsheet and analyzed using R software version 3.2.2. Heterogeneity between the infectious origins within the two populations and the eco-distribution of enteropathogens were assessed using the chi-square test and Fisher's exact tests. The Shannon diversity index made it possible to assess the bacterial and parasitic diversity observed. Crudes odds ratios (CORs) and $95 \%$ confidence intervals $(\mathrm{Cls})$ were used to assess the association between variables and occurrence of diarrhea. In addition, a factorial correspondence analysis was performed to assess the ecodistribution of enteropathogens. The statistical significance was set at $p<0.05$. 


\section{Results}

\section{Study population}

The children's demographic characteristics are summarized in Table 1.

Table 1

Distribution of diarrhea infection according to demographic data.

\begin{tabular}{|lccc|}
\hline \multirow{2}{*}{ Characteristics } & \multicolumn{2}{l}{ Number $(\%)$ of children } & Total $(n=132)$ \\
\cline { 2 - 3 } & $\begin{array}{l}\text { Diarrhea cases } \\
(n=102)\end{array}$ & $\begin{array}{c}\text { Control } \\
(n=30)\end{array}$ \\
\hline Sex & $54(52.9)$ & $14(46.7)$ & $68(51.1)$ \\
\hline Male & $48(47.1)$ & $16(53.3)$ & $64(48.5)$ \\
\hline Female & 1.13 & 0.88 & 1.06 \\
\hline Sex-ratio (M/F) & & \\
\hline Age groups (months) & $10(33.4)$ & $55(41.6)$ \\
\hline 0-24 & $45(44.1)$ & $10(33.3)$ & $43(29.5)$ \\
\hline $25-48$ & $29(28.4)$ & $10(33.3)$ & $16(28.8)$ \\
\hline $49-70$ & $28(27.5)$ & & \\
\hline
\end{tabular}

A total of 132 children aged from 0 to 70 months old were included, among whom 102 had a diarrheal syndrome and 30 were controls. Overall, the sex ratio was 1.06 (68 males and 64 females). The sex ratios for the children with diarrhea and the control group were 1.13 (54 males and 48 females) and 0.088 (14 males and 16 females), respectively. The mean age of the children included in the study was $32,6 \pm 20,6$ months old. Diarrheal syndrome was predominantly found in children aged 0 to 24 months old with a prevalence of $44.1 \%$. Prevalence of diarrheal syndrome was $28.4 \%$ and $27.5 \%$ in children aged 25 to 48 months old and 49 to 70 months old, respectively.

Clinical examination revealed that the most frequent signs associated with diarrhea were fever (26.5\%; $\mathrm{n}$ $=27 / 102)$, the association of fever and vomiting (16.7\%; $n=17 / 102)$ and vomiting $(5.9 \% ; n=6 / 102)$. These signs were assessed according to the usual clinical criteria: weight-to-height and height-to-age ratio, vomiting and fever. In addition to diarrhea, $11.8 \%$ of children had other conditions. Thirty-three (32.4\%) of the 102 subjects with diarrhea were on treatment; with a prevalence of $15.7 \%$ for antiparasitic treatments, $6.9 \%$ for traditional treatment, $5.9 \%$ for antibiotic therapy and $3.9 \%$ with antibioticantiparasitic combination (data not showed).

\section{Eco-distributions of germs and specific richness}


The distribution and classification of pathogens responsible for diarrhea in the children study population are summarized in Table 2. Microscopic examination of the 132 stool samples revealed that $71.2 \%$ of stool cultures were positive vs. 6.1\% negative. Overall, 228 germs were isolated including 199 (87.3\%) bacterial strains and 29 parasites (12.7\%). Opportunistic pathogens were more common in both diarrheal cases $(53.1 \%, n=121 / 228)$ and controls $(21.5 \%, n=49 / 228)$ than strict enteropathogens $(24.1 \%, n=$ $55 / 228 ; 1.3 \% n=3 / 228$ ) in diarrheal cases and controls, respectively. No strict enteropathogenic bacteria in controls were detected compared to diarrhea cases (16.2\%). In parasite infections, $7.9 \%$ of strict enteropathogens and $2.6 \%$ of opportunistic pathogens were isolated from diarrhea cases. In controls, the prevalence rates were $1.3 \%$ and $0.9 \%$ for strict enteropathogens and opportunistic pathogens, respectively.

Table 2

Eco-distribution of the total germs isolated in the study according to the type of the population.

\begin{tabular}{|llll|}
\hline & Number of cases (\%) & $\begin{array}{l}\text { Diarrheal cases } \\
\mathbf{n}(\%)\end{array}$ & $\begin{array}{l}\text { Control } \\
\mathbf{n}(\%)\end{array}$ \\
\hline Bacteria & $\mathbf{1 9 9 ( 8 7 . 3 )}$ & $152(66.7)$ & $47(20.6)$ \\
\hline Strict enteropathogens & $37(16.2)$ & $0(0.0)$ \\
\hline Opportunistic pathogens & $29(12.7)$ & $115(50.4)$ & $47(20.6)$ \\
\hline Parasites & $24(10.5)$ & $5(2.2)$ \\
\hline Strict enteropathogens & $18(7.9)$ & $3(1.3)$ \\
\hline Opportunistic pathogens & $6(2.6)$ & $2(0.9)$ \\
\hline
\end{tabular}

\section{Specific richness of the parasitic strains isolated from the study population}

The parasitic strains isolated are summarized in Table 3. In parasitic infections, the highest prevalence was observed with the Rhizopoda class (37.9\%), which accounts for the highest prevalence of parasitic infections detected among diarrhea cases. The second most prevalent class was Nematoda $(20.7 \%)$, followed by Trematodes (Schistosomes; $6.9 \%$ ) and Flagellata (6.9\%). Among Trematodes, Schistosoma mansonni (3.4\%) and intercalatum (3.4\%) were the two species detected. In Flagellata, Giardia intestinalis was detected (6.9\%). Entamoeba coli (20.7\%) was the most prevalent Rhizopod, Dientamoeba fragilis (3.4\%), Entamoeba hartmani (3.4\%), and Entamoeba hystolitica/dispar (3.4\%) had the same prevalence. In the Nematoda class, the highest prevalence was observed with Ascaris lumbricoides (10.3\%), followed by Ancylostoma duodenale (6.9\%) and Trichuris trichiura (3.4\%). Moreover, some parasitic species were also isolated in the controls among which Ancylostoma duodenale (3.4\%) and Ascaris lumbricoides (3.4\%) for the Nematodes, and Entamoeba coli (6.9\%) for the Rhizopoda class. Blastocystis hominis was isolated both in diarrhea cases and in controls with prevalence rates of $10.3 \%$ and $3.4 \%$, respectively. The 
overall diversity of the parasites was assessed by the Shannon index which was valued at 2.2. The difference was not statistically significant for all parasites between diarrhea cases and controls.

Table 3

Profile of parasitic strains isolated in patients.

\begin{tabular}{|c|c|c|c|}
\hline & Cases detected & Diarrhea cases & Control \\
\hline & $N=29$ & $\mathrm{n}(\%)$ & $\mathrm{n}(\%)$ \\
\hline Flagellates & & $2(6.9)$ & $0(0.0)$ \\
\hline Giardia intestinalis & & $2(6.9)$ & $0(0.0)$ \\
\hline Nematodes & & $6(20.7)$ & $2(6.9)$ \\
\hline Ancylostoma duodenale & & $2(6.9)$ & $1(3.4)$ \\
\hline Ascaris lumbricoides & & $3(10.3)$ & $1(3.4)$ \\
\hline Trichuris trichiura & & $1(3.4)$ & $0(0.0)$ \\
\hline Rhizopods & & $11(37.9)$ & $2(6.9)$ \\
\hline Dientamoeba fragilis & & $1(3.4)$ & $0(0.0)$ \\
\hline Endolimax nanus & & $2(6.9)$ & $0(0.0)$ \\
\hline Entamoeba coli & & $6(20.7)$ & $2(6.9)$ \\
\hline Entamoeba hartmani & & $1(3.4)$ & $0(0.0)$ \\
\hline Entamoeba histolytica/dispar & & $1(3.4)$ & $0(0.0)$ \\
\hline Schistosoma & & $2(6.9)$ & $0(0.0)$ \\
\hline Schistosoma mansonni & & $1(3.4)$ & $0(0.0)$ \\
\hline Schistosoma intercalatum & & $1(3.4)$ & $0(0.0)$ \\
\hline \multicolumn{4}{|l|}{ NS } \\
\hline Blastocystis hominis & & $3(10.3)$ & $1(3.4)$ \\
\hline Total & & 24 (82.8\%) & $5(17.2 \%$ \\
\hline
\end{tabular}

NS: not specified by systematic.

\section{Specific richness of Enterobacteriaceae strains isolated from the study population}

Opportunistic pathogens were more common than strict enteropathogens (Table 4). Strict enteropathogens were found in $18.6 \%(n=37 / 199)$ of the diarrhea samples. The highest prevalence was for Salmonella $\operatorname{spp}(8.6 \%)$, followed by Salmonella enterica $(3.0 \% ; \mathrm{n}=6 / 199)$, Salmonella Typhi $(2.0 \% ; \mathrm{n}=$ 
4/199) and Salmonella Paratyphi A (1.5\%) serovars of this species, whereas the genera Shigella and Yersinia were the least represented. The global prevalence of opportunistic pathogens was higher among diarrhea samples (57.8\%) compared to control samples (23.6\%) (see Table 4). Out of the 17 isolated species, the highest prevalence recorded was for E. coli 1 (25.2\% for diarrhea cases and $11.6 \%$ for controls), followed by Raoultella ornithinolytica ( $11.6 \%$ for diarrhea cases and $3.0 \%$ for controls), Kluyvera $\operatorname{spp}$ (2.5\% for diarrhea cases and controls, respectively), and Serratia fonticola ( $2.5 \%$ for diarrhea cases). 
Table 4

Profile and diversity of enterobacteria in the study.

\begin{tabular}{|c|c|c|c|}
\hline & Cases detected 199 & $\begin{array}{l}\text { Diarrhea cases } \\
\mathrm{n}(\%)\end{array}$ & $\begin{array}{l}\text { Control } \\
n(\%)\end{array}$ \\
\hline Strict enteropathogens & & $37(18.6)$ & - \\
\hline Salmonella enterica & & $6(3.0)$ & - \\
\hline Salmonella Paratyphi A & & $3(1.5)$ & - \\
\hline Salmonella spp & & $17(8.6)$ & - \\
\hline Salmonella Typhi & & $4(2.0)$ & - \\
\hline Shigella sonnei & & $2(1.0)$ & - \\
\hline Shigella spp & & $3(1.5)$ & - \\
\hline Yersinia pestis & & $2(1.0)$ & - \\
\hline Opportunistic pathogens & & $115(57.8)$ & $47(23.6)$ \\
\hline Citrobacter braakii & & $1(0.5)$ & - \\
\hline Citrobacter freundii & & $1(0.5)$ & - \\
\hline Citrobacter koseri & & $1(0.5)$ & $1(0.5)$ \\
\hline Enterobacter aerogenes & & $4(2.0)$ & - \\
\hline Enterobacter cloacae & & $2(1.0)$ & $1(0.5)$ \\
\hline Escherichia coli 1 & & $50(25.2)$ & $23(11.6)$ \\
\hline Escherichia coli 2 & & $3(1.5)$ & $3(1.5)$ \\
\hline Escherichia vulneris & & $2(1.0)$ & - \\
\hline Klebsiella oxytoca & & $3(1.5)$ & - \\
\hline Klebsiella pneumoniae & & $4(2.0)$ & $1(0.5)$ \\
\hline Kluyvera spp & & $5(2.5)$ & $5(2.5)$ \\
\hline Pantoea spp & & $1(0.5)$ & $1(0.5)$ \\
\hline Raoultella ornithinolytica & & $23(11.6)$ & $6(3.0)$ \\
\hline Raoultella terrigena & & $4(2.0)$ & - \\
\hline Serratia fonticola & & $5(2.5)$ & $2(1.0)$ \\
\hline Serratia liquefaciens & & $2(1.0)$ & - \\
\hline Serratia odorifera 1 & & $4(2.0)$ & $4(2.0)$ \\
\hline
\end{tabular}


Regardless of the bacterial species, 7 pathogens were isolated only in diarrhea samples including Enterobacter aerogenes (2.0\%), Raoultella terrigina (2.0\%), Klebsiella oxytoca (1.5\%), Escherichia vulneris (1.0\%), Serratia liquefaciens (1.0\%), Citrobacter braakii $(0.5 \%)$, and freundii $(0.5 \%)$. The results of the Shannon Diversity Index showed a great diversity of bacteria within the study population $(\mathrm{H}=2.48$ and 1.68 for diarrheal and control cases, respectively). The Pielou Fairness Index showed that the observed diversity was due to the high abundance of $E$. coli in both cases and controls $(\mathrm{J}=0.7)$.

\section{Spatial distribution of isolated germs}

The spatial distribution of the bacterial and parasite species detected in the study population in KoulaMoutou is presented in Fig. 2. There was no species representative of a district.

Regardless of the bacterial species, bacterial diversity was higher in the Mikoumou district with 11 different species including Citrobacter freundii and koseri, Enterobacter aerogenes, Escherichia coli, Klebsiella oxytoca and pneumoniae, Kluyvera spp, Pantoea spp, Raoultella ornithinolytica, Serratia fonticola and Yersinia pestis belonging to 9 genera (Citrobacter, Enterobacter, Escherichia, Klebsiella, Kluyvera, Pantoea, Raoultella, Serratia and Yersinia). The Bakélé and Bambomo districts harbored 8 different species. Escherichia coli 1 and 2, Klebsiella pneumoniae, Kluyvera spp, Raoultella ornithinolytica and terrigena, Salmonella Paratyphi $A$ and Shigella sonnei, belonging to 6 genera (Escherichia, Klebsiella, Kluyvera, Raoultella, Salmonella and Shigella) were found in the Bambomo district. For the Bakélé district Enterobacter aerogenes and cloacae, Escherichia coli 1 and vulneris, Salmonella enterica and spp, Shigella spp and Yersinia pestis, belonging to 5 genera (Enterobacter, Escherichia, Salmonella, Shigella and Yersinia) were found. Seven species including Citrobacter braakii, Escherichia coli 1, Klebsiella pneumoniae, Raoultella ornithinolytica, Salmonella spp, Serratia fonticola and Shigella spp, belonging to 5 different genera (Citrobacter, Escherichia, Klebsiella, Raoultella, Salmonella, Serratia, and Shigella) were found in the Mayéla district. The Concorde (Enterobacter aerogenes, Raoultella ornithinolytica,

Salmonella enterica and Serratia liquefaciens and odorifera 1), and Jardin-Four-TP (Escherichia coli 1 and 2, Klebsiella oxytoca, Kluyvera spp and Raoultella ornithinolytica) districts presented intermediate diversities with 5 different species. Four species were also found in Konadembé (Escherichia coli 1, Salmonella enterica, Serratia liquefaciens and Raoultella ornithinolytica belonging Escherichia, Salmonella, Serratia and Raoultella genera), in Makadium (Enterobacter cloacae, Escherichia coli 1, Raoultella ornithinolytica and terrigena belonging to the Enterobacter, Escherichia, and Raoultella genera) and in Ménage (Escherichia coli 1, Raoultella ornithinolytica and terrigena and Salmonella spp belonging to Escherichia, Salmonella and Raoultella), respectively. In the rest of the districts, 3 species belonging to various genera were isolated (see Fig. 2). The same profile was observed for Bouvendo (Escherichia coli 1 and 2 and Salmonella spp) and Koungou (Escherichia coli 1, Salmonella Paratyphi A and spp), Centreville and Mandji-Château (Escherichia coli 1, Raoultella ornithinolytica and Salmonella spp), Lenguébé/Pembébé (Escherichia coli 1, Salmonella spp and Serratia oderifera 1), Litsébé (Escherichia coli 1, Salmonella enterica and Serratia oderifera 1), and Mikalou (Escherichia coli 1, Salmonella Typhi and Serratia fonticola) districts. The Mandji-Boungouêret district presented a different profile (Enterobacter aerogenes, Escherichia coli 1 and Klebsiella pneumoniae). Babambo (Escherichia coli 1 and Raoultella 
ornithinolytica), Dakar (Escherichia coli 1 and Shigella spp) and Moukouagna (Salmonella spp and Typhi) presented 2 different genera or the same Salmonella genus, respectively.

The distribution of bacterial and parasitic enteropathogens by district is presented in Fig. 3 .

The enteropathogens were mainly distributed in the city center of Koula-Moutou $(73.9 \%, n=17 / 23)$. In 7 of the 17 districts, two different bacterial and parasitic species were isolated including Salmonella spp and Ancylostoma duodenale in Balomba, Salmonella spp and Ascaris lumbricoides in Bouvendo, Salmonella Typhi and Ancylostoma duodenale in the city center, Salmonella enterica and Schistosoma intercalum in Concorde, Salmonella spp and Giardia intestinalis in Mandji-Château, Salmonella Typhi and Ascaris lumbricoides in Mikalou and Yersinia pestis and Ancylostoma duodenale in Mikoumou. However, for the 2 other districts, 3 species were isolated including 2 bacterial species and 1 parasitic species. For the Mayéla district, the pathogens isolated were Salmonella spp, Shigella spp and Endolinax nanus and Salmonella Paratyphi A, Salmonella spp and Ascaris lumbricoides for the Koungou district. In the 8 other districts, only bacterial enteropathogens were found. Mapping showed that some pathogens were specific to a few districts. In fact, Shigella spp was isolated in patients from Dakar, Salmonella Paratyphi A from Mibaka, Salmonella enterica from Litsébé, and Salmonella spp from diarrheal patients from the Ménage district. However, a diversity of species was recorded in the Bakélé (Salmonella enterica, Salmonella spp and Shigella spp), Konadembé (Salmonella enterica and Shigella sonnei) and Moukouagna (Salmonella spp and Typhi) districts.

\section{Enteric organisms associated with diarrhea}

Bacterial etiology is the most observed with a prevalence of $25.5 \%(26 / 102)$ in diarrheal cases compared to $0.0 \%(0 / 30)$ for controls. However, the prevalence of parasitic etiology for diarrhea is $20.6 \%(21 / 102)$. In controls, this prevalence is $10.0 \%(3 / 30)$ (no statistically significant difference).

Salmonella spp (29.4\%) was the most prevalent enteric pathogen in diarrheal cases, followed by Entamoeba spp (7.8\%), Shigella spp (4.9\%), Ascaris lumbricoides and Blastocystis hominis (3.0\%). The most common enteric pathogens among controls were Entamoeba spp with 6.7\%, Ancylostoma duodenale, Ascaris lumbricoides, and Blastocystis hominis which account for respectively 3.3\% (see Table 5). Entamoeba spp was significantly associated with diarrhea (OR 1.8, 95\% $\mathrm{Cl} 0.21-12.13$ ). Other organisms were not significantly associated with diarrhea in this study (Table 5). 
Table 5

Prevalence of microorganisms in cases and controls and their association with diarrhea.

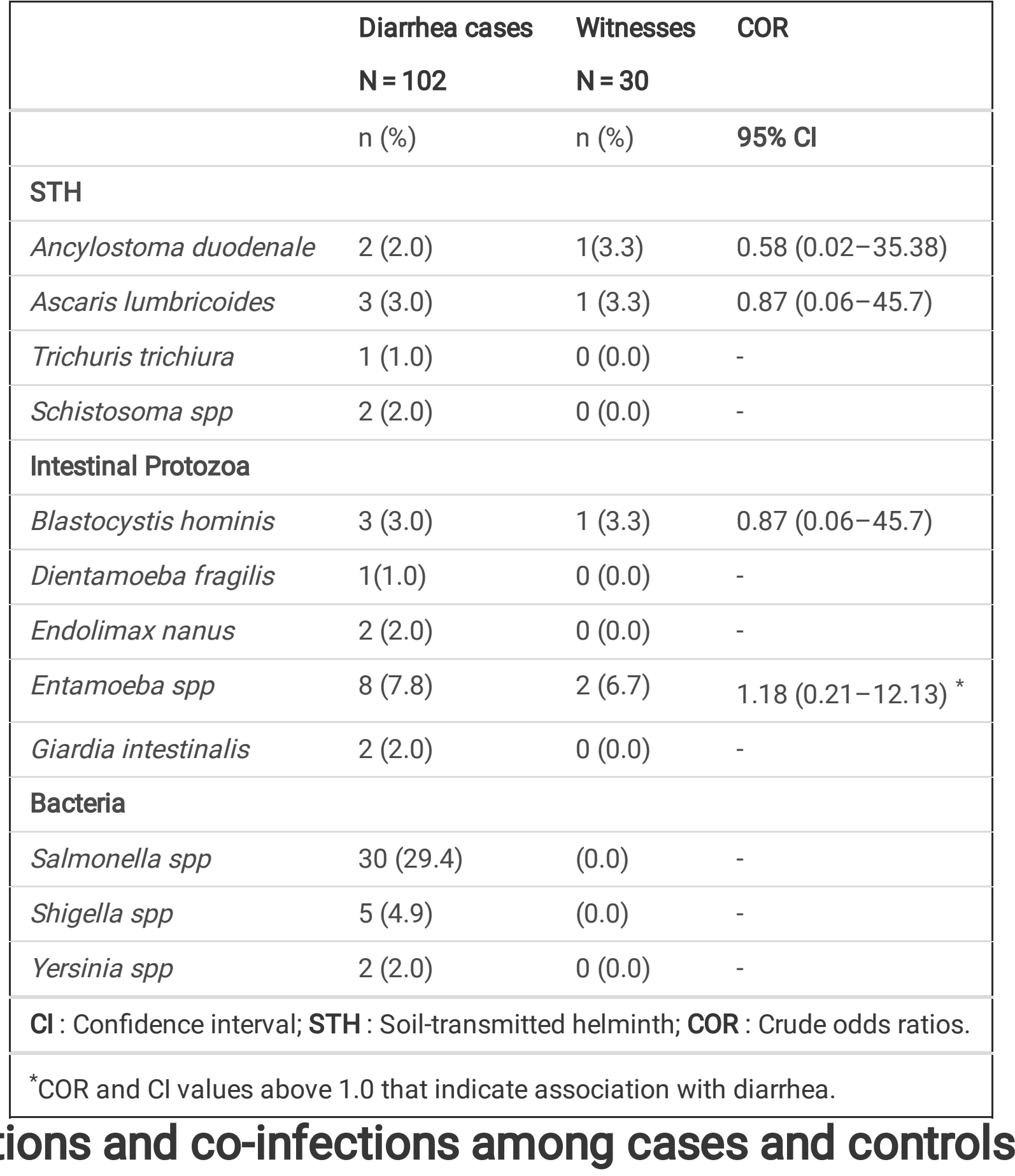

Microscopic examination revealed at least one pathogen in 50 positives stools samples with a $37.9 \%$ global prevalence. Among positive stool samples, $46.1 \%$ of diarrheal cases were infected, vs. $10.0 \%$ $(3 / 30)$ in controls. This stool examination did not lead to the detection of strict pathogens among the 132 participants examined. However, opportunistic pathogens were detected in 82 children (62.1\%) among which 53.9\% (55/102) in diarrheal cases and 90.0\% (27/30) in controls $(p<0.001)$. The frequency of single and multiple infections was analyzed in all populations. Multiple infections predominated (34.8\% versus $25.8 \%$ for single infections) (see Table 5). Multiple infections carrying two to four different pathogens were detected in children, including 33.3\% (34/102) in diarrheal cases and $10.0 \%$ in controls 
$(p=0.011)$. Thirty of the children with multiple infections and diarrhea harbored two pathogens $(29.4 \%)$. The most representative multiple infections are parasite-opportunistic bacteria (13.7\%) and Salmonella spp - opportunistic bacteria (10.8\%) for co-infections. The least representative are Salmonella Entamoeba coli (2.0\%) and Salmonella spp-Shigella spp (1.0\%), Salmonella spp-Giardia intestinalis (1.0\%), Shigella spp-opportunistic bacteria (1.0\%). Three of them harbored three and four pathogens (2.9\% and $1.0 \%$, respectively). Salmonella spp - Shigella spp - Yersinia spp, Salmonella - opportunistic bacteria - Dientamoeba fragilis and Shigella spp - opportunistic bacteria - Entamoeba coli were found with the same prevalence (0.9\%), and Salmonella spp - opportunistic bacteria - Endolimax nanus Entamoeba hystolitica/dispar were found with a prevalence of $1.0 \%$. Three $(10.0 \%)$ children with multiple infections in the control group harbored two pathogens (10.0\%) among which Ancylostoma duodenaleopportunistic bacteria (3.3\%), Ascaris lumbricoides - opportunistic bacteria (3.3\%) and Blastocystis hominis - opportunistic bacteria (3.3\%) were found.

\section{Distribution between enteropathogens and age groups}

The distribution of the different species of enteropathogens according to the different age groups was determined using the correspondence factor analysis (CFA) (Fig. 4). The results of the distribution of enteropathogens according to age groups showed that parasitic enteropathogens, including Entamoeba hystolitica, Dientamoeba fragilis, Schistosoma intercalatum and Schistosoma mansonni were mainly associated with children aged 0 to 24 months old. This same association is found for Salmonella enterica. Enteropathogens of the Shigella genus including shigella spp, shigella sonnei, as well as Yersinia spp and Endolimax nanus were associated with children aged 25 to 48 months old. Salmonella thyphi and Salmonella paratyphi $A$ were associated with children aged 49 to 70 months old. No association between age groups and pathogens was found for Giardia intestinalis, Ancylostoma duodenale and Salmonella spp.

\section{Risk factors among environmental determinants for infections due to enteropathogens}

Potential risk factors (drinking water, type of toilet, watercourses, domestic animals, and sanitation of the plot) associated with diarrheal diseases are summarized in Table 6. 
Table 6

Determinants of diarrhea in children of Koula-Moutou.

$\begin{array}{llll}\text { Characteristics } & \begin{array}{l}\text { Diarrhea cases }(n= \\ 102)\end{array} & \begin{array}{l}\text { Control } \\ (n=30)\end{array} & \text { COR (Cl 95\%) }\end{array}$

\section{Housing conditions}

Drinking water

\begin{tabular}{lllll} 
Tap & $70(68.6)$ & $\begin{array}{l}18 \\
(60.0)\end{array}$ & $1.5(0.45-5.43)^{\star}$ & 0.59 \\
\hline Public pump & $22(21.5)$ & $\begin{array}{l}11 \\
(36.7)\end{array}$ & $0.83(0.15-4.64)$ & 0.8 \\
River & $2(2.0)$ & $1(3.3)$ & $/$ & $/$ \\
Well & $1(1.0)$ & $0(0.0)$ & $/$ & $/$ \\
\hline Source & $1(1.0)$ & $0(0.0)$ & $/$ & $/$ \\
Rain & $2(2.0)$ & $0(0.0)$ & $/$ & $/$ \\
Water treatment & $4(3.9)$ & $0(0.0)$ & $/$ & \\
\hline Type of sanitary facilities & & & & \\
\hline Modern latrines & $41(40.2)$ & $9(30.0)$ & $1.56(0.2-10.91)^{*}$ & 0.7 \\
Traditional latrines & $61(59.8)$ & 21 & $1.37(0.45-4.41)$ & 0.6 \\
& & $(70.0)$ & &
\end{tabular}

\section{Watercourses}

$\begin{array}{lllll}\text { Rivers } & 22(21.6) & 5(16.7) & 4(0.30-214.2)^{*} & 0.2 \\ \text { Puddles } & 20(19.6) & 6(20.0) & / & 0.06 \\ \text { Wastewater } & 6(5.9) & 3(10.0) & 1(0.01-34.08) & / \\ \text { Absence } & 54(52.4) & 16 & 0.76(0.2-2.65) & 0.6\end{array}$

\section{Domestic Animals}

$\begin{array}{lllll}\text { Hens and roosters } & 21(20.6) & 6(20.0) & 2.66(0.29-34.43)^{*} & 0.3 \\ \text { Sheep } & 1(1.0) & 0(0.0) & / & / \\ \text { Dogs/cats } & 20(19.6) & 6(20.0) & 2.69(0.21- & 0.62 \\ & & 142.12)^{*} & \end{array}$

Mixed : herbs + garbage bins/farms ; $\mathrm{Cl}$ at $95 \%$ : confidence intervals at 95\%, COR : crude odds ratios. The percentages are will reference to totals given at the top of each column. Odd ratios obtained by logistic regression. ${ }^{*} \mathrm{COR}$ and $\mathrm{Cl}$ values above 1.0 that indicate association with diarrhea 


\begin{tabular}{|c|c|c|c|c|}
\hline Characteristics & $\begin{array}{l}\text { Diarrhea cases }(n= \\
102)\end{array}$ & $\begin{array}{l}\text { Control } \\
(n=30)\end{array}$ & COR (Cl 95\%) & $p$-Value \\
\hline Mixed & $28(27.5)$ & $8(26.7)$ & $1(0.15-6.55)$ & / \\
\hline $\begin{array}{l}\text { Absence of domestic } \\
\text { animals }\end{array}$ & $32(31.4)$ & $\begin{array}{l}10 \\
(33.3)\end{array}$ & $1.02(0.19-5.97)$ & l \\
\hline \multicolumn{5}{|l|}{ Sanitation of the parcel } \\
\hline Herbs & $87(85.3)$ & $\begin{array}{l}26 \\
(86.7)\end{array}$ & $1.6(0.59-4.55)^{*}$ & 0.3 \\
\hline Garbage bins & $7(6.9)$ & $1(3.3)$ & / & / \\
\hline Farms & $2(2.0)$ & $0(0.0)$ & l & / \\
\hline Mixed & $6(5.9)$ & $3(10.0)$ & $1(0.02-88.07)$ & l \\
\hline \multicolumn{5}{|c|}{$\begin{array}{l}\text { Mixed : herbs + garbage bins/farms ; Cl at } 95 \% \text { : confidence intervals at } 95 \%, \text { COR : crude odds ratios. } \\
\text { The percentages are will reference to totals given at the top of each column. Odd ratios obtained by } \\
\text { logistic regression. }{ }^{*} \mathrm{COR} \text { and } \mathrm{Cl} \text { values above } 1.0 \text { that indicate association with diarrhea }\end{array}$} \\
\hline
\end{tabular}

The results showed that more than half of the population consumed water from taps $(68.6 \%$ for diarrheal cases vs $60.0 \%$ for controls). Regarding amenities, the majority of children used traditional latrines (59.8\% in diarrheal cases and $70.0 \%$ in controls, respectively). An unsanitary condition found for plots was the presence of grass ( $85.3 \%$ and $86.7 \%$ for diarrheal cases and controls, respectively). Although no significant association between the different potential risk factors and the occurrence of diarrhea was observed, the data showed that the presence of a watercourse in the immediate environment increased the risk of diarrhea in children which was multiplied by 4 , as well as the presence of domestic animals such as chickens and dogs / cats which multiplied the risk by 2.66 and 2.69 , respectively.

\section{Discussion}

This study on diarrheal disease in Gabonese children is the first to assess the etiology of diarrheal syndromes in Koula-Moutou, Gabon. While data on adults and children already exist, children under 5 years old with diarrheal syndromes living in the semi-urban environment of the city of Koula-Moutou have not been previously studied.

In this study, the prevalence of children aged up to 5 years with diarrhea was $77.3 \%$, it is similar to that reported by a previous study in another city in Gabon (21). The results of our study also showed that $41.6 \%$ of the children with diarrhea were aged 0 to 24 months old and were the most affected age group with a prevalence of $44 \%$. Our results corroborate those of several studies led in Africa, with a higher prevalence found in children aged 0 to 12 months $(8,16,22,23)$. This predominance could be explained by the fact that generally, between 6 to 23 months of age, children are more vulnerable compared to those aged over 36 months old (24). Indeed, pathologies such as diarrhea are recurrent in this age group due to 
the gradual decline in maternal antibodies as well as the introduction of new dietary practices sometimes correlated with poor hygienic practices $(24,25)$.

A range of different pathogenic organisms can cause pediatric diarrhea in the world, especially in tropical and developing countries, including rotaviruses and adenoviruses (26), intestinal parasites such as Giardia intestinalis, Entamoeba histolytica (27), and bacteria such as Escherichia coli, Shigella spp, Salmonella, Campylobacter spp (8). This study shows a strong heterogeneity of parasites and bacteria in diarrheal cases in which most of the species are not isolated in control cases. The most common parasitic species isolated in diarrheal cases were Entamoeba spp, Ascaris lumbricoides, Blastocystis hominis, Ancylostoma duodenale, Giardia intestinalis, Endolimax nanus, Schistosoma spp and Trichuris trichiura. This profile is similar to that reported in previous studies $(28,29)$. In addition, Ascaris lumbricoides, Blastocystis hominis, Giardia intestinalis, Entamoeba spp and Trichuris trichiura appear to be the intestinal parasites most frequently involved in parasitic infections in Gabon (20). These species have a worldwide distribution and are characteristic of some countries (30). Regarding the bacterial group, 11 genera belonging to the Enterobacteriacea family were recorded, a similar profile was found in the work of Mbuthia et al. in Kenya. The diversity was specific to the Enterobacteriaceae, Pseudomonaceae and Vibrionaceae families (2). This bacterial diversity was marked by a clear predominance of Escherichia coli strains with an isolation rate of $26.6 \%$, which is similar to other studies with variable frequencies $(25,31,32)$. Likewise, this study isolated a high rate of bacteria less commonly incriminated for causes of diarrhea and belonging to the Raoultella, Serratia, Klebsiella, Enterobacter, Citrobacter and Pantoea genera (31.1\%). Previous studies reveal that some of these strains, such as the Citrobacter spp and Klebsiella spp species, have acquired specific virulence genes, which can induce diarrhea and / or hemorrhagic colitis $(2,33)$.

Pathogen infection was significantly more prevalent in patients with diarrhea, with a prevalence of $46.1 \%$ compared to controls $(10.0 \%)$. These results are similar to those reported by other studies $(34,35)$. On the other hand, this overall prevalence of pathogens recorded in diarrheal cases in this study was lower than those obtained by Okon et al. in Nigeria and Knee et al. in Mozambique who found prevalence rates of $61.8 \%$ and $86 \%$, respectively $(23,32)$. This contrast could probably be related to the lack of characterization of diarrheagenic Escherichia coli (DEC) in this study. Furthermore, this study also shown the presence of parasitic pathogens in this population, with a frequency of $20.6 \%$. This prevalence was, however, lower than that recorded in Nigeria (37.1\%) (32), Cameroon (59.2\%) (7) and Gabon (61.0\%) (21). The high prevalence of infections due to bacterial pathogens in these conditions is similar to that found in other studies $(8,23)$.

One of the particularities of this study was the lack of bacterial pathogens isolated from controls. The frequency of bacterial infections $(25.5 \%)$ is higher than that reported in a previous study by Koko et al. carried out in Libreville (17) who obtained a prevalence of $12.9 \%$. This variability in epidemiological characteristics could undoubtedly be linked to the level of urbanization of the two zones, the environmental conditions and hygiene of the respective populations, which are all factors that influence the etiology of diarrheal diseases $(9,36)$. Salmonella spp strains were the most predominant in the 
bacterial profile of this study and accounted for $29.4 \%$. This prevalence is in contrast with the one obtained in previous studies concerning developing countries, and particularly countries in the African region where the prevalence was markedly lower $(37,38)$. However, these data corroborate the work of Koko et al. in Gabon (17) and Rathaur et al. in India (39). Indeed, these studies identified Salmonella spp as a major etiological agent responsible for diarrhea. In addition, its presence could be correlated with domestic animals like poultry, which could constitute reservoirs of infection and a potential source of Salmonella diarrhea (7). The prevalence rates of the Shigella and Yersinia strains observed in this study, $4.9 \%$ and $2.0 \%$ respectively, can be explained by the epidemiological heterogeneity of the geographical areas $(32,37,40,41)$.

In this research, multiple infections of enteric pathogens were more found in diarrheal cases than in controls. This has also been reported in other studies particularly in patients with low or average income $(35,42)$. These results would suggest that more than one pathogen was responsible for the diarrheal disease in children living in Koula-Moutou. The presence of mixed infections complicates the diagnosis of a specific pathogen responsible for the disease and may result in an additive effect, which may lead to new clinical profiles (42). A reliable basic diagnosis must be established for better patient care and treatment.

Factorial correspondence analysis (CFA) reveals a predominance of parasites, Salmonella and Shigella in children over 12 months old. The parasitic data from this study are comparable to the literature which highlights an increase in parasitic infections in subjects over 12 months of age, for which the most likely explanation would be frequent contact with soil $(7,43)$. Likewise, this distribution of bacterial strains has already been reported by other authors $(17,23,39)$.

The transmission and spread of diarrheal diseases are closely linked to environmental factors but also to living conditions, personal hygiene, behavior and domestic environment (44). In this study, univariate analysis of the data showed that the presence of rivers and domestic animals were the risk factors significantly associated with the occurrence of diarrhea in the town of Koula-Moutou. These results are consistent with the data reported by Bouba Djourdebbé et al. (24). Watercourses create a habitat conducive to the proliferation of microorganisms. Combined with other parameters, such as the proximity of animals which are potential pathogen reservoirs and the lack of knowledge on good hygiene practices, the presence of rivers influences the risk of contamination $(24,45)$. Given that diarrheal diseases can be linked to the presence of feces in water, the population of Koula-Moutou can be highly exposed to this health risk. Indeed, this city has a very dense water network which unfortunately serves for domestic use but in which wastewater containing the feces of some animals or even humans can be thrown away. These practices can obviously contribute to the fairly high prevalence of diarrheal diseases in this area.

This study has some limitations. It used only microbiological analyzes, including stool bacterial cultures, as they are the most common diagnostic routine methods used in developing countries. Stool culture may have a lower sensitivity of detection of bacterial pathogens than PCR, which allows the discrimination of different pathotypes and a better appreciation of the involvement of multiple infections 
with enteric pathogens associated with diarrhea (42). Moreover, the low proportion of controls in this study may not be representative of the correlation between enteric pathogens and acute diarrhea.

\section{Conclusion}

This preliminary study in the city of Koula-Moutou on children with diarrhea reveals a great diversity of enterobacteria and parasites. Although the profile of pathogenic enterobacteriaceae strains is very classic, this study highlights a high prevalence of unusual bacteria which may be involved in childhood diarrhea. The map of the distribution of pathogens shows no particular characteristic in any area of the city. In addition, the occurrence of diarrhea in this city is linked to environmental determinants such as the presence of rivers and animals.

Faced with this diversity of microorganisms and risk factors, further data are needed to develop a better mapping of the widespread strains and improve etiological knowledge. These studies would help to target and broaden preventive and treatment strategies for diarrheal disease.

\section{Abbreviations}

CFA: Correspondence factor analysis; PMRHC: Paul Moukambi Regional Hospital Center; Cl: Confidence interval; ACC: Ambulatory care center; COR: Crud odd ratio; HIV: Human immunodeficiency virus; STH: Soil-transmitted helminth; WHO: World Health Organization.

\section{Declarations}

\section{Acknowledgements}

All the authors are deeply grateful for the participation of the children and parents from Koula-Moutou in this study. We also wish to thank the clinicians and laboratory workers CHRPM and CTA for their assistance and their time and effort. We would also like to acknowledge Jim Randy ABONGO, Arlet BOUNGOINDZI and Claudel Yannick C FOUTY DITONA for making the maps.

\section{Funding}

Not applicable.

\section{Authors' contributions}

RMM, JFY and SLOL coordinated the study, performed the statistical analysis, conducted data analysis and wrote the manuscript. RMM was the principal investigator of the study, collected all data in the field, collected biological samples and carried out the microbiological analyses. RMM and MGM coordinated the field study at PMRHC and AMD was the physician of the study. FM carried out statistical analyses and the interpretation of data. SED contributed to the writing of the manuscript. JFY, AS and JBLD 
conceived, designed and coordinated the study, and conducted data analysis. All authors have read and approved the final manuscript.

\section{Availability of data and materials}

The datasets that were used for the analysis and the preparation of this manuscript are available from the corresponding author upon reasonable request.

\section{Ethics approval and consent to participate}

This is detailed in the "Methods" section.

\section{Consent for publication}

Not applicable.

\section{Competing interests}

The authors declare that they have no competing interests.

\section{Author details}

1Laboratoire de Biologie Moléculaire et Cellulaire, équipe de Microbiologie (LABMC), Unité de recherche Agrobiologie, Université des Sciences et Techniques de Masuku (USTM), BP 067 Franceville, Gabon. 2Unité d'Evolution, Epidémiologie et Résistance Parasitaire (UNEEREP), Centre International de Recherches Médicales de Franceville (CIRMF), BP 769 Franceville, Gabon. 3Laboratoire de Recherche en Immunologie, Parasitologie et Microbiologie (LRIPM), Ecole Doctorale Régionale d'Afrique Centrale en Infectiologie Tropicale ; Université des Sciences et Techniques de Masuku (USTM), BP : 876 Franceville, Gabon. 4Laboratoire d'Ecologie Vectorielle, LEV, Institut de Recherche en Ecologie Tropicale (IRET), BP 13354, Libreville, Gabon. 5Centre de Traitement Ambulatoire de Koula-Moutou, BP : 876 Koula-Moutou, Gabon. 6Unité de Transfusion Sanguine, Laboratoire d'Analyses Biomédicales, Centre Hospitalier Régional Paul Moukambi (CHRPM), BP : 03, Koula-Moutou. 7Département de Parasitologie-Mycologie Médecine Tropicale, Faculté de Médecine, Université des Sciences de la Santé, BP 4009 Libreville, Gabon.

\section{References}

1. OMS. Groupe inter organisations pour l'estimation de la mortalité juvénile 2015. 2015.

2. Mbuthia OW, Mathenge SG, Oyaro MO, Ng'ayo MO. Etiology and pathogenicity of bacterial isolates: a cross sectional study among diarrheal children below five years in central regions of Kenya. Pan Afr Med J. 2018;31(88):1-14.

3. Getu D, Gedefaw M, Abebe N. Childhood Diarrheal Diseases and Associated Factors in the Rural Community of Dejen District, Northwest. Am Sci Res J Eng Technol Sci. 2014;1:1-13. 
4. Murongo Kanyande A. Bilan épidémiologique des maladies diarrhéiques d'origine hydro-fécale dans la zone de santé rurale de Walikale. Ann I'UNIGOM. 2017;7(1):349-62.

5. Koné B, Doumbia M, Sy I, Dongo K, Agbo-Houenou Y, Houenou PV, et al. Étude des diarrhées en milieu périurbain à Abidjan par l'approche écosanté. VertigO - la Rev électronique en Sci l'environnement. 2014;1-20.

6. Aubry P, Gaüzère B-A. Diarrhées infectieuses. Médecine Trop. 2018;1-8.

7. Yongsi HBN. Pathogenic Microorganisms associated with childhood diarrhea in Low-and-Middle Income Countries: Case study of Yaoundé - Cameroon. Int J Environ Res Public Heal 2008. 2008;5:213-29.

8. Bonkoungou IJO, Haukka K, Österblad M, Hakanen AJ, Traoré AS, Barro N, et al. Bacterial and viral etiology of childhood diarrhea in Ouagadougou , Burkina Faso. BMC Pediatr. 2013;13(36):1-6.

9. Fontoura VM, Graepp-Fontoura I, Santos FS, Santos Neto M, Santos de AlmeidaTavares H, Bezerra $\mathrm{MOL}$, et al. Socio-environmental factors and diarrheal diseases in under five-year old children in the state of Tocantins, Brazil. Riddle MS, éditeur. PLoS One. 13(5):1-13. http://dx.plos.org/10.1371/journal.pone.0196702

10. Cherkaoui A, Emonet S, Renzi G, Schrenzel J. Diagnostic de la gastroentérite bactérienne. Rev Med Suisse. 2015;11:856-61.

11. Gebresilasie YM, Tullu KD, Yeshanew AG. Resistance pattern and maternal knowledge, attitude and practices of suspected Diarrheagenic Escherichia coli among children under 5 years of age in Addis Ababa, Ethiopia: Cross sectional study. Antimicrob Resist Infect Control. 2018;7(110):1-9.

12. Troeger C, Khalil IA, Rao PC, Cao S, Blacker BF, Ahmed T, et al. Rotavirus Vaccination and the Global Burden of Rotavirus Diarrhea among Children Younger Than 5 Years. JAMA Pediatr. 2018;172(10):958-65.

13. Reiner RC, Graetz N, Casey DC, Troeger C, Garcia GM, Mosser JF, et al. Variation in Childhood Diarrheal Morbidity and Mortality in Africa, 2000-2015. New Engl J o f Med. 2018;379:1128-38.

14. DGS, ICF. Enquête Démographique et de Santé du Gabon 2012: rapport de synthèse. 2012;1-20.

15. Makita-lkouaya E, Mombo JB, Milleliri JM, Rudant JP. Étude de la morbidité exprimée à Libreville (Gabon) en 2008. Med Sante Trop. 2013;23:324-7.

16. Nzame Vierin $Y$, Mengue M'Ella M, Ngoubeyou M, Moussavou A. Prise en charge pré hospitalière de la Diarrhée chez l'enfant de moins de 5 ans à Libreville. Heal Sci Dis. 2015;16(4):1-4.

17. Koko J, Ategbo S, Gahouma D. Epimiologie des diarrhées aiguës bactériennes de l'enfant à Libreville, Gabon. Arch Pédiatrie. 2013;XXX(1):1-2.

18. Pottier P, Allogho-Nkoghe F-M, Koumba J-P, Ntsame Ondo N. L'urbanisation à l'assaut du littoral du Gabon. In: Interactions Nature-Société. Coédition. 2017. p. 181-95.

19. Mukabutera A, Thomson D, Murray M, Basinga P, Nyirazinyoye L, Atwood S, et al. Rainfall variation and child health: effect of rainfall on diarrhea among under 5 children in Rwanda, 2010. BMC Public Health. 2016;16(731). http://dx.doi.org/10.1186/s12889-016-3435-9 
20. M'bondoukwé NP, Kendjo E, Mawili-Mboumba DP, Koumba Lengongo VJ, Offouga Mbouoronde C, Nkoghe D, et al. Prevalence of and risk factors for malaria , filariasis , and intestinal parasites as single infections or co-infections in different settlements of Gabon, Central Africa. BMC Infect Dis Poverty. 2018;7(6):1-17.

21. Oyegue-Liabagui SL, Ndjangangoye NK, Kouna LC, Lekolo GM, Mounioko F, Nolna SK, et al. Molecular prevalence of intestinal parasites infections in children with diarrhea in Franceville, Southeast of Gabon. BMC Infect Dis. 2020;20(350):1-11. https://doi.org/10.1186/s12879-02005071-x

22. Gupta A, Sarker G, Rout AJ, Mondal T, Pal R. Risk Correlates of Diarrhea in Children Under 5 Years of Age in Slums of Bankura, West Bengal. J Glob Infect. 2015;7(1):23-30.

23. Knee J, Sumner T, Adriano Z, Berendes D, De Bruijn E, Id OC, et al. Risk factors for childhood enteric infection in urban Maputo, Mozambique: A cross- sectional study. PLoS Negl Trop Dis. 2018;12(11):1-19.

24. Bouba Djourdebbé F, Dos Santos S, Legrand TK, Bassiahi Soura A. Influence des facteurs environnementaux et démographiques dans la cooccurrence de la diarrhée et de la fièvre chez les enfants dans cinq quartiers périphériques de Ouagadougou (Burkina Faso). Cah québécois démographie [Internet]. 2015;44(1):35. http://id.erudit.org/iderudit/1032148ar

25. Kouéta F, Ouédraogo SY, Dao L, Ouédraogo RT, Sanou I, Yé D. Etiologies infectieuses des diarrhées aigües de l'enfant de 0 à 5 ans au Centre Hospitalier Universitaire Pédiatrique Charles de Gaulle (Ouagadougou, Burkina Faso). Mali Med. 2014;53-7.

26. Munnink BBO, van der Hoek L. Viruses Causing Gastroenteritis: The Known, The New and Those Beyond. Viruses. 2016;8(42):1-10.

27. Abdel-Hafeez EH, Belal US, Abdellatiff MZM, Naoi K, Norose K. Breast-Feeding Protects Infantile Diarrhea Caused by Intestinal Protozoan Infections. Korean J Parasitol. 2013;51(5):519-24.

28. Boughattas S, Behnke JM, Al-ansari K, Sharma A. Molecular Analysis of the Enteric Protozoa Associated with Acute Diarrhea in Hospitalized Children. Front Cell Infect Microbiol. 2017;343:1-10.

29. Villamizar X, Higuera A, Herrera G, Vasquez-a LR, Buitron L, Muñoz LM, et al. Molecular and descriptive epidemiology of intestinal protozoan parasites of children and their pets in Cauca, Colombia: a cross- sectional study. BMC Infect Dis. 2019;19(190):1-11. https://doi.org/10.1186/s12879-019-3810-0\%0A

30. Gyang VP, Chuang T, Liao C, Lee Y, Akinwale OP, Orok A, et al. Intestinal parasitic infections: Current status and associated risk factors among school aged children in an archetypal African urban slum in Nigeria. J Microbiol Immunol Infect. 2017;20:1-8. http://dx.doi.org/10.1016/j.jmii.2016.09.005

31. Korie F, Ikefuna A, Ibe B. Bacterial Agents Associated With Acute Diarrhoea In Under-5 in Enugu, Nigeria. J Dent Med Sci. 2012;2(6):40-5.

32. Okon KO, Nguru MG, Bularafa MY, Mohammed HU, Baba ZA, Hamza U, et al. Enteropathogens Associated with Childhood Diarrheal Cases seen at a Tertiary Hospital in Nguru , Yobe State of Nigeria. Br Microbiol Res J. 2014;4(5):583-91. 
33. Cheng VCC, Yam W-C, Tsang L-L, Yau MCY, Siu GKH, Wong SCY, et al. Epidemiology of Klebsiella oxytoca -associated Diarrhea detected by Simmons Citrate agar supplemened with inositol, tryptopha and bile salts. J Clin Microbiol. 2012;50(5):1571-9.

34. Breurec S, Vanel N, Bata P, Chartier L, Farra A, Favennec L, et al. Etiology and Epidemiology of Diarrhea in Hospitalized Children from Low Income Country: A Matched Case-Control Study in Central African Republic. PLoS Negl Trop Dis. 2016;10(1):1-18.

35. Farfán-García AE, Imdad A, Zhang C, Arias-Guerrero MY, Sánchez-Álvarez NT, Iqbal J, et al. Etiology of acute gastroenteritis among children less than 5 years of age in Bucaramanga, Colombia: A casecontrol study. PLoS Negl Trop Dis. 2020;14(6):1-20.

36. Ateudjieu J, Bita'a Beyala L, Guenou E, Chebe AN, Chukuwchindun BA, Goura AP, et al. Profil et antibiosensibilité des bactéries pathogènes associées aux diarrhées chez les patients consultants à I'Hôpital Régional Annexe de Kousseri, Extrême-Nord Cameroun. Pan Afr Med J. 2018;29(170):1-12.

37. Moyo SJ, Gro N, Matee MI, Kitundu J, Myrmel H, Mylvaganam H, et al. Age specific aetiological agents of diarrhoea in hospitalized children aged less than five years in Dar es Salaam, Tanzania. BMC Pediatr. 2011;11(19):1-6. http://www.biomedcentral.com/1471-2431/11/19

38. Andrianarivelo AM, Rakotondraoelina LM, Ratsimbazafy ABA, Andriamandimbisoa TH, Rafaramalala SS, Rafalimanana C, et al. Bacterial Diarrhea in Antananarivo: Place of Salmonella spp and Shigella spp in Stool Culture. Int J Curr Microbiol Appl Sci. 2016;5(2):110-5.

39. Pathania M, Rathaur VK, Jayara A, Yadav N. Clinical Study of Acute Childhood Diarrhoea Caused by Bacterial Enteropathogens. J Clin Diagnostic Res. 2014;8(5):1-5.

40. Sang WK, Oundo V, Schnabel D. Prevalence and antibiotic resistance of bacterial pathogens isolated from childhood diarrhoea in four provinces of Kenya. $J$ Infect Dev Ctries. 2012;6(7):572-8.

41. Okolo MO, Garba DE, Stephen E. Isolation and prevalence of bacteria associated with diarrhea in children visiting hospitals in ANYIGBA. Journal, Am Sci Nat. 2013;1(8):121-9.

42. Harb A, Abraham S, Rusdi B, Laird T, O'Dea M, Habib I. Molecular Detection and Epidemiological Features of Selected Bacterial , Viral, and Parasitic Enteropathogens in Stool Specimens from Children with Acute Diarrhea in Thi-Qar Governorate, Iraq. Int J Environ Res Public Health. 2019;15(1573):1-16.

43. Nicolas X, Chevalier B, Simon F, Klotz F. Traitement des parasitoses intestinales (amibiase et mycoses exclues). Encycl Médico-Chirurgicale, Mal Infect. 2002;8-518-A15:1-14.

44. Rautu L, Dos Santos S, Schoumaker B. Facteurs de risque pour les maladies diarrhéiques chez les enfants à Dakar: une analyse multi-niveaux avec variables latentes. African Popul Stud. 2016;1:2203-12.

45. Attia AR, Sackou-Kouakou J, Claon S. Déterminants de la diarrhée chez l'enfant de moins de 5 ans vivant dans les quartiers précaires d'ABIDJAN (2007). Rev Int Sc Méd. 2013;15(3):119-23.

\section{Figures}




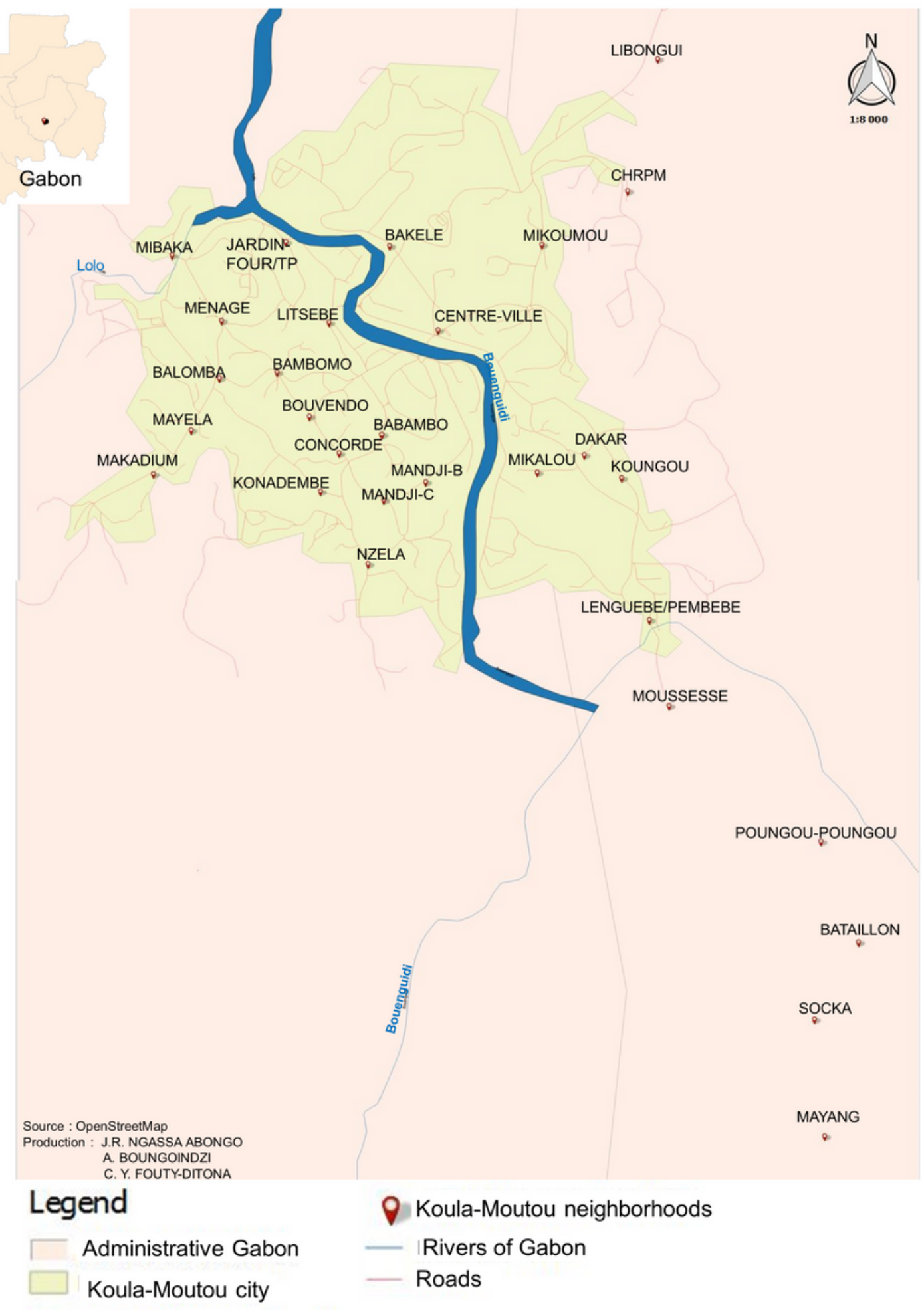

\section{Figure 1}

Map of the city of Koula-Moutou Legend: The background map in pink represents administrative Gabon and in yellow the city of Koula-Moutou. The lines in blue represent rivers and in red the roads, and the red location markers represent the neighborhoods. 


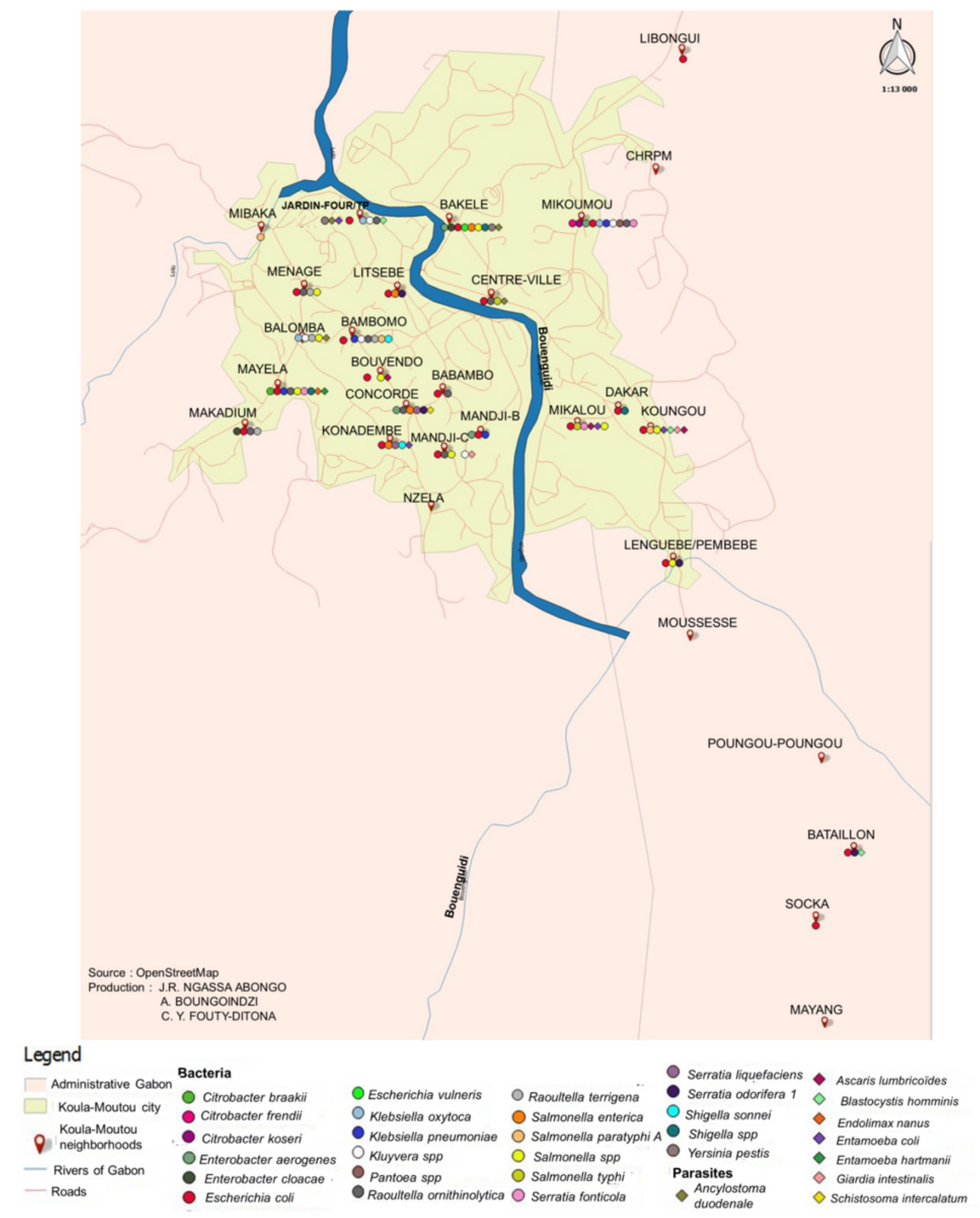

\section{Figure 2}

Map of the diversity of microorganisms isolated in the case-control study. Mandji-C: Mandji-Castle; Mandji-B: Mandji-Bougoueret. Legend: The background map in pink represents administrative Gabon and in yellow the city of Koula-Moutou. The lines in blue represent rivers and in red the roads, and the red location markers represent the neighborhoods. The circles in different colors represent the different bacterial species and the triangles represent the various parasitic species 


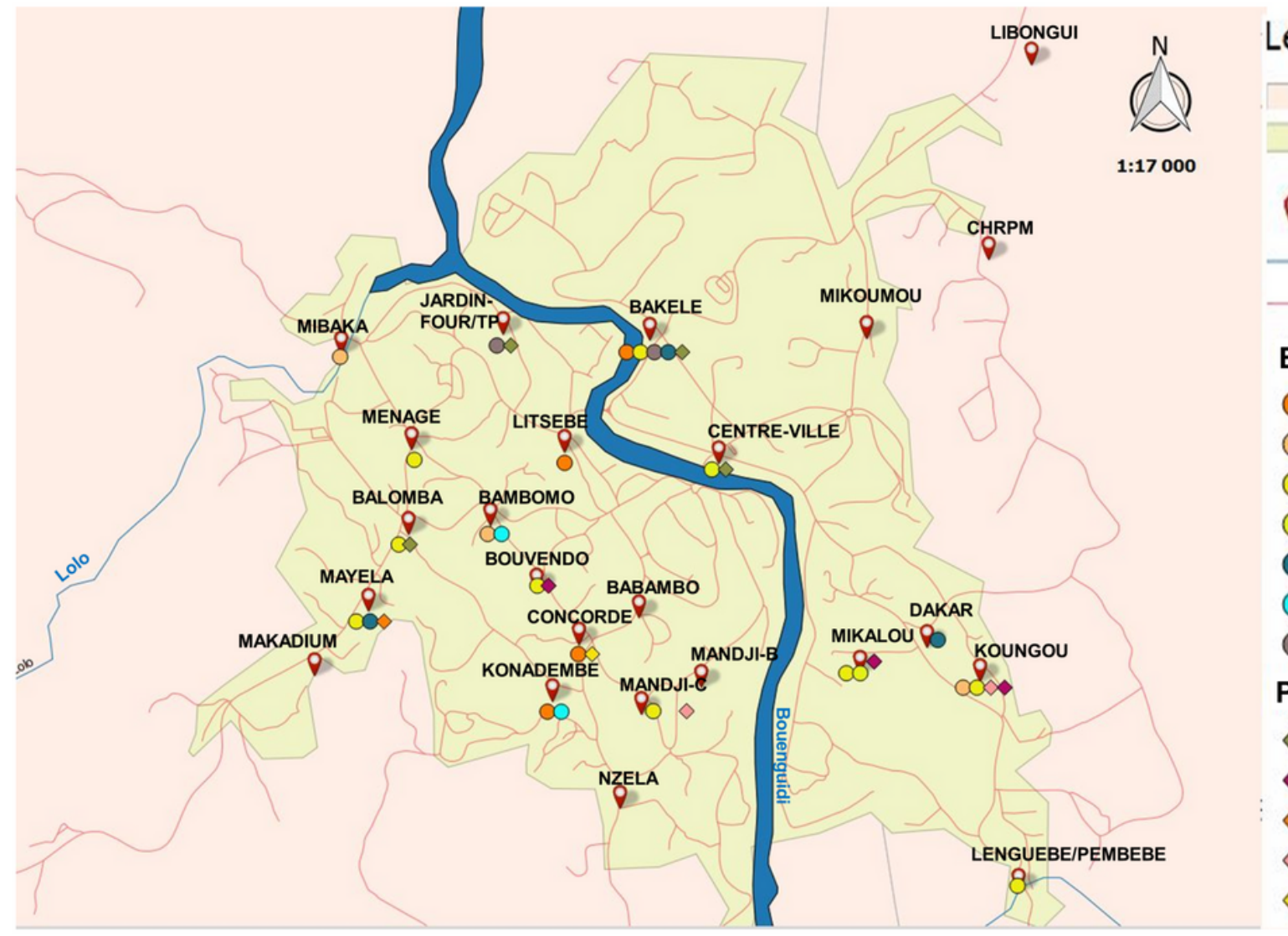

Legend

Administrative Gabon
Koula-Moutou city
Koula-Moutou
neighborhoods
Rivers of Gabon
Roads
Bacteria

- Salmonella enterica

Salmonella paratyphi $A$

Salmonella spp

Salmonella typhi

- Shigella spp

Shigella sonnei

- Yersinia pestis

Parasites

Ancylostoma duodenale

- Ascaris lumbricoïdes

$\diamond$ Endolinax nanus

$\diamond$ Giardia intestinalis

$\checkmark$ Schistosoma intercalatum

\section{Figure 3}

Spatial distribution of enteropathogens in the city of Koula-Moutou. Legend: The background map in pink represents administrative Gabon and in yellow the city of Koula-Moutou. The lines in blue represent rivers and in red the roads, and the red location markers represent the neighborhoods. The circles in different colors represent the different pathogenic bacterial species and the triangles represent the various pathogenic parasitic species. 


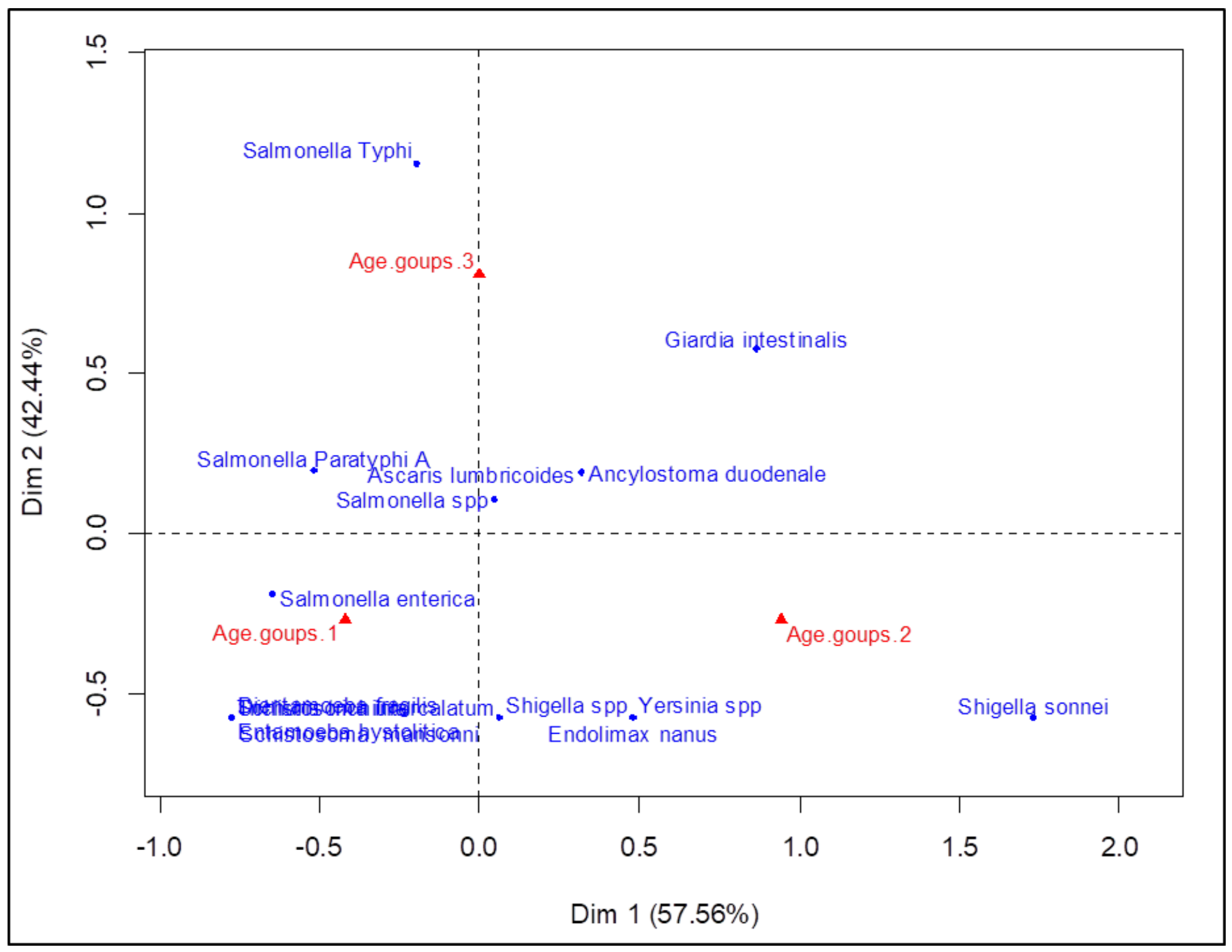

\section{Figure 4}

Distribution of enteropathogens by age group. Legend: The triangles on the map represent the different age groups and the dots represent enteric pathogens (Age group 1: 0 - 24 months; Age group 2: $25-48$ months; Age group 3: 49 - 70 months). 